\title{
Research on valuation of water system in source region of the yellow river based on emergy theory
}

\author{
Yongqiang Wang, Zhiming Liu, Zhe Yuan*, Jijun Xu and Jin Chen \\ Hubei Provincial Key Laboratory of Basin Water Resources and Ecological Environment, Yangtze River Scientific Research Institute, \\ Wuhan, China
}

\begin{abstract}
Taking the source region of the Yellow River as an example, this paper first introduces the theory of energy value and its basic steps. Then combined with the Yellow River source area, the variation characteristics of precipitation and surface water resources from 1961 to 2011 in the Yellow River source area were analyzed, and both of them showed a trend of decreasing year by year. On this basis, using the theory of energy value, combined with relevant parameters, taking 2011 year as an example, further analyses the chemical energy and solar energy of water resources in the Yellow River source area, and gives the value of surface water resources. The value of water resources per unit is $1.59 \mathrm{yuan} / \mathrm{m} 3$. For the Yellow River source area, the overall value of water resources for the whole basin in 2011 is 33.55 billion yuan. It can provide a reference for the analysis of the value of surface water resources in the Yellow River Basin.
\end{abstract}

\section{Introduction}

With the rise of the quantitative research on the value of ecosystem services to natural capital, the ecological service function of water has received increasing attention. How to objectively understand and measure the true value of water resources, as well as quantitative, objective and scientific evaluation of the structural state of water resources composite systems, is the basis for formulating countermeasures for sustainable use and management of water resources. How to quantify the resource and environmental value and its effects in the composite system, and explore an objective scale to measure the logistics, energy flow and value flow to achieve the integration of society, economy and ecology, which is the key to solving the water resource problem. Where. On the whole, the current assessment of the ecological benefits of water is mainly based on the ecological service function of water. Relevant scholars carried out water ecological service function evaluation, estimated the total value of water ecosystem, and analyzed the ecological economy and sustainable assessment of resources at different time and space scales. At the same time, the evaluation of water ecological service functions is carried out for different objects such as wetlands, cities, agriculture, and nature reserves. The theory and method of value (Emergy) is a theory and method developed on the basis of system ecology and ecosystem energetics. It is a new theoretical system for quantitatively measuring the value of natural resources. The ability to analyze the value of the traditional economic value analysis to disable the monetary measurement of ecosystem services can be compensated for by the natural energy value analysis method. Based on the natural attributes of hydrological cycle and water resources, this paper quantitatively studies the value of natural water resources by using energy value analysis method, and proposes an energy value assessment method based on emergy theory for natural water resources value, which can be used for sustainable use of water resources. Management provides scientific data references and decision making.

\section{Study area and data}

\section{1 study area}

The source area of the Yellow River is located in the Yellow River basin in the northeastern part of the Qinghai-Tibet Plateau. It covers 6 states and 18 counties in the three provinces of Qinghai, Sichuan and Gansu. The drainage area is 122,000 square kilometers, accounting for $16 \%$ of the total area of the Yellow River Basin. The average elevation of the Yellow River source area is about 3,000 meters, and the source area is as high as 4,400 meters. It is one of the most abundant highaltitude areas in the world, and has an important impact on the water ecological environment of the Yellow River Basin.

\footnotetext{
"Corresponding author: yuanzhe_0116@126.com
} 


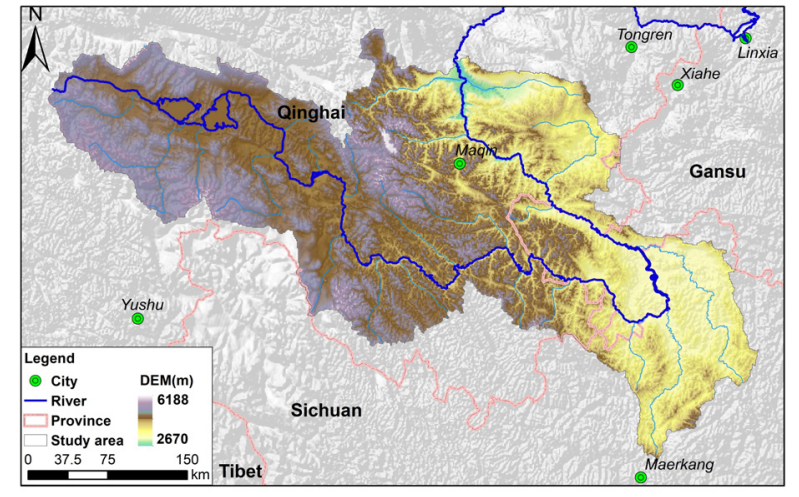

Figure 1. The location of the study area

\section{2 data}

The observed daily precipitation data during 1961 to 2011 from 26 meteorology stations in and around the YRB were collected for this study (Fig.1), which is provided by China Meteorological Data Sharing Service System (http://data.cma.gov.cn). The Daily precipitation data for each meteorological station was reorganized into annual precipitation. Then the data was converted into grid maps via the co-kriging method with the help of a digital elevation model (DEM) (Fig.2). Using the GRID function of ARC/INFO, annual areal mean precipitation can be obtained via ZONALSTATS (Fig.4a).

The discharge data was collected from Tangnaihai stations during the period from 1961 to 2011 (Fig.3). It was used to analyze the discharge trend (Fig.4b) and the change of the precipitation-discharge relationship (Fig.5). The hydrological data is derived from National Integrated Water Resources Planning and Yellow River Conservancy Commission of the Ministry of Water Resources (http://www.yellowriver.gov.cn).

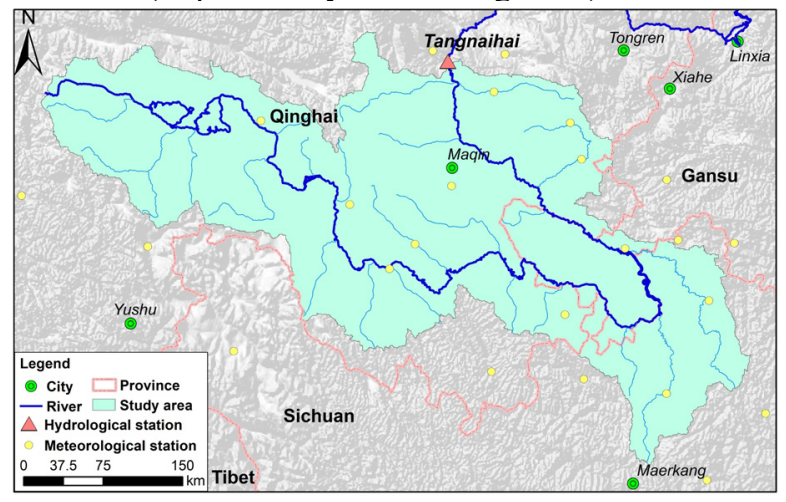

Fig.2 The meteorological/hydrological stations used in this study

\section{Methodology}

\subsection{Emergy theory}

The emergy theory was established by the ecologist H.T.Odum in the 1980s. It uses the solar energy value as a unified standard to comprehensively analyse the conversion mechanism of various energy flows of the eco-economic system, and to determine the ecological and economic benefits. The theory adopts a consistent energy value standard, and uses a uniform energy value standard as a dimension to convert the energy flow, logistics, and currency flow of different measurement units into a uniform energy value and energy value. The conversion rate can convert different types of substances or energy in the ecosystem into energy values of the same standard to quantitatively analyse and evaluate its role and status in the system. The energy conversion rate is an indicator of the energy quality level of different classes of substances or energy. The higher the energy conversion rate of a substance or energy, the higher the energy value and the higher the level of the energy system. Using the energy value theory, the energy flow of the ecosystem and the ecological benefit capital stock can be calculated.

Compare with other methods such as Ecological footprint and lifecycle assessment. Ecological footprint and emergy analysis methods pay more attention to environmental resource utilization and environmental carrying capacity assessment. The former focuses on consumption assessment, while the latter focuses on input assessment. Life cycle assessment is mainly applied to the safe production of products in industrial production processes. Environmental impact assessment, energy value analysis extends the research area of energy and material accumulation and transformation, and achieves a unified measure of different qualitative energy at different energy levels. Table 1 gives the indices of emergy anlysis.

Table 1 indices of emergy analysis

\begin{tabular}{|c|c|c|}
\hline parameter & formula & meaning \\
\hline $\mathrm{T}$ & $\mathrm{sej} / \mathrm{J}$ or $\mathrm{kg}$ & $\begin{array}{l}\text { The amount of solar } \\
\text { energy contained in } \\
\text { each unit of energy. }\end{array}$ \\
\hline Em & $\mathrm{EmR}+, \mathrm{EmN}+, \mathrm{EmF}$ & $\begin{array}{l}\text { The total amount of } \\
\text { direct/indirect solar } \\
\text { energy required for the } \\
\text { formation of energy, etc. }\end{array}$ \\
\hline EPA & $\mathrm{Em} / \mathrm{A}$ & $\begin{array}{l}\text { Reflecting the strength } \\
\text { and level of economic } \\
\text { development of the eco- } \\
\text { economic system }\end{array}$ \\
\hline ...... & ...... & ...... \\
\hline Em\$ & $\mathrm{Em} /(\mathrm{Em} / \$)$ & $\begin{array}{l}\text { Reflecting the value of } \\
\text { resource energy value to } \\
\text { the economy }\end{array}$ \\
\hline ELR & $(\mathrm{EmF}+\mathrm{EmN}) / \mathrm{EmR}$ & $\begin{array}{l}\text { Measuring the pressure } \\
\text { of the natural } \\
\text { environment }\end{array}$ \\
\hline
\end{tabular}

\subsection{Emergy evaluation step}

After continuous improvement and development, the value analysis has gradually formed more stylized methods and steps:

1)Collecting research objects related to energy flow, material flow, and currency flow Data.

2)Determine the main energy and components of the system and plot the energy value system. Firstly, according to the research content, the boundary of the 
system diagram is determined, and then the main energy source of the system is determined according to the principle of determining the main energy. Finally, the conversion rate of the solar energy value represented by the energy is sorted within and outside the system boundary.

3)Prepare an energy value assessment analysis form to evaluate the contribution of environmental production to the economic system. The energy value analysis analysis table includes number, project, raw data, solar energy conversion rate, solar energy value and macroeconomic value.

4)According to the relevant data in the energy value evaluation analysis table, various energy value indicators reflecting the system energy value characteristics and the evaluation system structure function are calculated, and the contribution value of environmental production to the system is evaluated.

5)Through the calculation of various energy value indicators and analysis results, it helps people to correctly understand and evaluate the contribution of environmental production to the economic system, and provide a theoretical basis for scientific research work.

\section{Results and discussion}

\subsection{Relationship between precipitation and runoff in the source region of the Yellow River}

Based on the multi-year average rainfall data from 1961 to 2011 in the Yellow River source area, the spatial distribution of precipitation in the Yellow River source area was calculated, as shown in Figure 3.

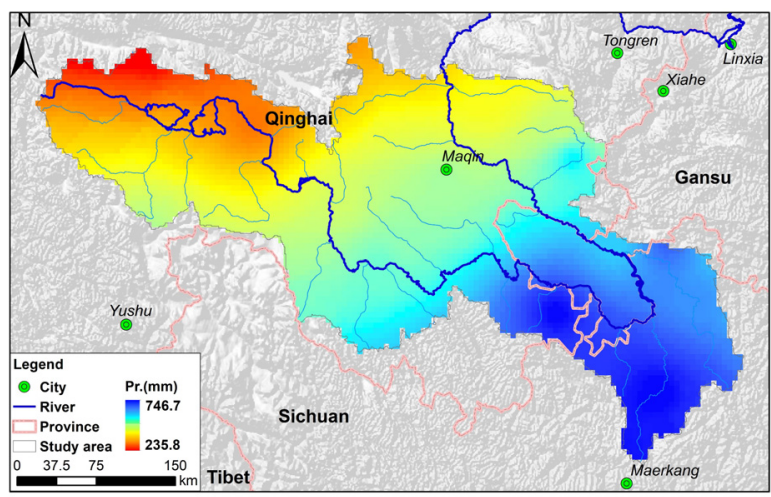

Fig.3 The average annual precipitation from 1961 to 2011

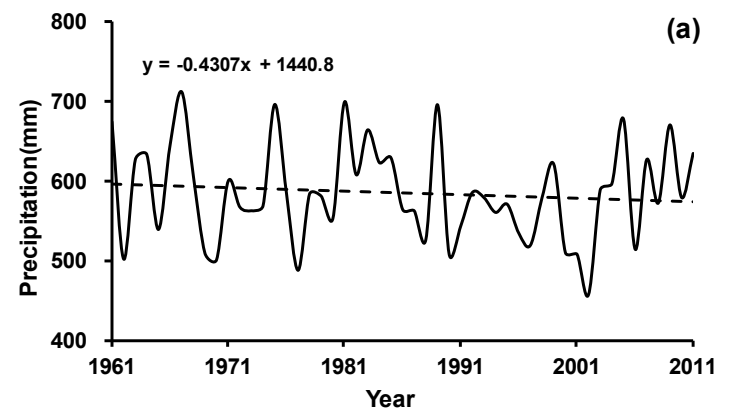

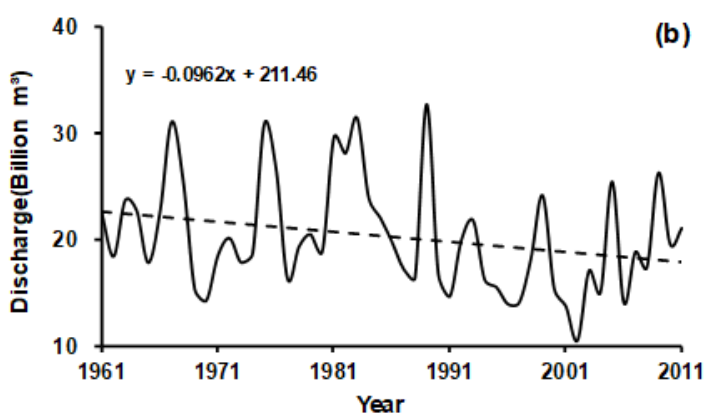

Fig.4 The precipitation (a) and discharge (b) from 1961 to 2011

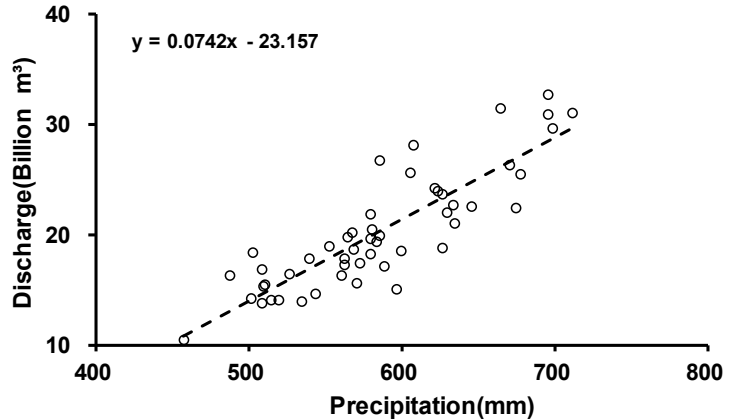

Fig.5 The relationship between precipitation and discharge

Fig.4(a) and fig.4(b) show that from 1961 to 2011, the precipitation and runoff of the Yellow River source area showed a gradual decline. Figure 5 shows that as the rainfall increases, the runoff in the source region of the Yellow River increases, and the two show a positive correlation.

\subsection{Emergy evaluation}

As the year of 2011, the precipitation is $634.8 \mathrm{~mm}$, and the amount of surface water resources in the Yellow River source area is 21.1 billion $\mathrm{m}^{3}$, which is slightly less than the average of $10 \%$. Table 2 and Table 3 gives the Energy analysis of precipitation and surface water resources of 2011. The relevant parameters are selected as follows: due to the effect of atmospheric circulation, the solar energy conversion rate of rainwater has not changed in a certain range. The solar energy conversion rate of rainwater is selected to be $1.82 \mathrm{sej} / \mathrm{J}$, and the Gibbs free energy of rainwater is taken as $4.94 \mathrm{~J} / \mathrm{g}$, the average solid matter dissolved amount of rainwater and surface water is $10,56.9 \mathrm{ppm}$ respectively; rainwater, the density of surface water and groundwater is $1 \times 10 \mathrm{~g} / \mathrm{m}$, and the density of Yellow River water is $1.1 \times 10^{6} \mathrm{~g} / \mathrm{m}^{3}$. The annual energy/currency ratio of the study area is taken as $5.34 \times 10^{11} \mathrm{sej} / \mathrm{yuan}$. The value of water resources per unit is 1.59 yuan $/ \mathrm{m}^{3}$. For the Yellow River source area, the overall value of water resources for the whole basin in 2011 is 33.55 billion yuan.

Table 2. Energy analysis of precipitation of 2011

\begin{tabular}{|l|r|}
\hline Precipitation $/ \mathrm{mm}$ & 634.8 \\
\hline Rainwater chemical energy/J & $4.4 * 10^{15}$ \\
\hline Rainwater solar value/sej & $8.09 * 10^{19}$ \\
\hline
\end{tabular}

Table 3. Energy analysis of surface water resources of 2011 Surface water resources $/ \mathrm{m}^{3}$ 


\begin{tabular}{|l|c|}
\hline $\begin{array}{l}\text { Surface water resource chemical } \\
\text { energy/J }\end{array}$ & $105.5 * 10^{15}$ \\
\hline $\mathrm{T} / \mathrm{sej}^{*} \mathrm{~J}^{-1}$ & $407.9 * 10^{5}$ \\
\hline
\end{tabular}

\section{Conclusion}

Awareness of the value of water is of paramount importance to us. Taking the source region of the Yellow River as an example, this paper analyzes the trend of precipitation and surface runoff from 1961 to 2011 in the Yellow River source area, and gives the correlation between the two. On this basis, taking 2011 as an example, the chemical energy and solar energy of water resources in the source region of the Yellow River are further analyzed. At the same time, the value of surface water resources is given, which can provide reference for the analysis of surface water resources value in the Yellow River Basin.

\section{Acknowledgements}

This work is funded by the National Key R\&D Program of China(2017YFC0403600, 2017YFC0403606), the National Natural Science Foundation of China (No. 51779013, 51509009), National Public Research Institutes for Basic R\&D Operating Expenses Special Project (No.CKSF2017008), Water Conservancy Science and Technology Innovation project of GuangDong Province(2017-03). Special thanks are given to the anonymous reviewers and editors for their constructive comments.

\section{References}

1. H.T.Odum. Self-organization, Transformity, and Information. Science, 1988, (242): $1132 \sim 1139$.

2. H.T.Odum. Environmental Accounting: Emergy and Environmental Decision Making. John Wiley and Sons, 1995.

3. Brown, Mark T., and Sergio Ulgiati. "Emergy evaluations and environmental loading of electricity production systems." Journal of cleaner production 10.4 (2002): 321-334.

4. H.T.Odum, M. T. Brown, and S. Brandt-Williams. Handbook of emergy evaluation. Center for environmental policy, 2000.

5. ZHOU, J. B., et al. Emergy evaluations for constructed wetland and conventional wastewater treatments. Communications in Nonlinear Science and Numerical Simulation, 2009, 14.4: 1781-1789.

6. Bardi, E., et al. Emergy synthesis 7: theory and applications of the emergy methodology. Ed. Mark Theodore Brown. Center for Environmental Policy, University of Florida, 2013.

7. Buenfil, Andres A. Emergy evaluation of water. Diss. University of Florida, 2001.

8. DÍAZ-DELGADO, Carlos, et al. The establishment of integrated water resources management based on emergy accounting. Ecological engineering, 2014, 63: 72-87.

9. ZHONG, Shaozhuo, et al. Emergy-based sustainability evaluation of Erhai Lake Basin in China. Journal of Cleaner Production, 2018, 178: 142-153.

10. MELLINO, Salvatore; BUONOCORE, Elvira; ULGIATI, Sergio. The worth of land use: a GISemergy evaluation of natural and human-made capital. Science of the Total Environment, 2015, 506: 137-148 